\title{
Molecular Cloning of Retinoic-Acid Metabolizing Cytochrome P450 26B1 (Cyp26B1) and Expression Analysis during Different Reproductive Phase in Clarias magur (Hamilton 1822)
}

\author{
Deepak Agarwal ${ }^{1}$, P. Gireesh Babu ${ }^{1 *}$, Vandita Kohli ${ }^{2}$, Om Pravesh K. Ravi ${ }^{3}$, \\ Srijit Chakravarty ${ }^{3}$, Adnan Gora ${ }^{4}$ and Aparna Chaudhari ${ }^{1}$
}

${ }^{1}$ Fish Genetics and Biotechnology Division, ${ }^{2}$ Fish Post Harvest Management Division, ICARCentral Institute of Fisheries Education, Versova, Mumbai-400 061, India

${ }^{3}$ CoFS, BAU, Ranchi, India

${ }^{4}$ CMFRI, Kochi, India

*Corresponding author

\begin{tabular}{|l|}
\hline Ke y w o r d s \\
$\begin{array}{l}\text { Cyp26B1, Retinoic } \\
\text { acid, Preparatory } \\
\text { phase, Ovatide } \\
\text { Retinoid signalling }\end{array}$ \\
\hline Article Info \\
\hline $\begin{array}{l}\text { Accepted: } \\
\text { 06 July 2018 } \\
\text { Available Online: } \\
\text { 10 August } 2018\end{array}$ \\
\hline
\end{tabular}

A B S T R A C T

Retinoid signalling is crucial to vertebrate embryonic development. The Cyp26B1 is one of the key catabolic enzymes, involved in the inactivation of all-trans retinoic acid and helps in the maintaining of retinoic acid availability for retinoid signalling. In the present study, for the first time, we cloned and characterized the full coding sequence of Cyp26B1 gene in Clarias magur. The full-length cDNA sequence of Cyp26B1 gene was 1782 bp (ORF 1533 bp) encoding 511 amino acids. Signal peptide analysis revealed that Cyp26B1 is a secretory protein as reported in other vertebrates. The hydropathy profile predicted that Cyp26B1 is hydrophilic in nature. The overall quality factors of Cyp26B 1 protein by ERRAT analysis was $56.19 \%$, indicating the instability of proteins. The expression profile generated for the preparatory, spawning, $6 \mathrm{~h}$ and $16 \mathrm{~h}$ post Ovatide ${ }^{\mathrm{TM}}$ injection stages, revealed the significantly higher expression $(\mathrm{P}<0.05)$ of Cyp26B1 mRNA in the brain of female fish compared to the ovary at all developmental stages and peaked at spawning stage. Whereas in male fish, the mRNA expression was significantly higher at $16 \mathrm{~h}$ post Ovatide $^{\mathrm{TM}}$ injection stages in the brain and minor expression obtained at all the stages of testis. Our findings suggest that maintenance and clearance of retinoic acid are essential at every developmental stage in $C$. magur and Cyp26B1 might play important role in germ cell development ultimately affect the reproductive physiology.

\section{Introduction}

It is well studied that retinoids were involved in many developmental processes. Through binding to its receptors RARs and RXRs, retinoids participate in the retinoid signalling and ultimately control the sex-specific meiosis initiation timing and regulate spermatogenesis in vertebrates (Chung et al., 2004; Feng et al., 2015). However, vertebrates cannot synthesize 
the retinoids de novo while metabolize it from its precursor vit. A (Zhao et al., 2005). In all animal including vertebrates, vit. A which is essential in reproduction (Clagett-Dame and Knutson, 2011) is converted into trans tetinoic acid (RA) through retinol dehydrogenase enzymes (Aldh1a 1/2/3; Ross et al., 2000). Since any signalling is determined by the feedback processes, therefor excess RA is converted into its the inactive polar forms 4hydroxy-retinoic acid and 4-oxo-retinoic acid through the Cyp26s enzymes (Ross et al., 2000). In vertebrates, three Cyp26s (including Cyp26A1, Cyp26B1 and Cp26C1) have been reported which all involved in the catabolism of RA. Meiosis is an indispensable process of sexual reproduction which has been reported to be initiated at the same time in female and males (Pradhan et al., 2015).

The entry of germ cell into the meiotic stage is determined by the RA through star8 dependent pathway and the level of RA is finally regulated by the balance between its synthesis and degradation through Aldh1a 1/2/3 and Cyp26A1 and Cyp26B1 respectively (AbuAbed et al., 2001; Yashiro et al., 2004).

Cyp26A1 and Cyp26B1 exhibit less than 30\% amino acid identity with other cytochromes and therefore could not be classified into any of the previously defined subfamilies hence come under new P450 26 subfamily (Nelson et al., 1993). However, with only $40 \%$ sequence similarity between Cyp26A1 and Cyp26B1, broad expression pattern, different catalytic activities with no biologically important differences were reported between Cyp26A1 and Cyp26B1 in the formation of active metabolites of RA (Topletz et al., 2012). Recent studies in some fishes revealed that Cyp26A1, rather than Cyp26B1, was considered as the major RA degrading enzyme (Rodríguez-Marí et al., 2013; Lau et al., 2013; Feng et al., 2015). However, low or no expression of cyp26B1 induced an excessive initiation of meiosis, resulted in the apoptosis of pre-matured spermatogonia through an elevated level of RA (MacLean et al., 2007). Only a few reports on the characterisation of this gene are available in fish making it difficult to understand its actual function.

Clarias magur, the Indian walking catfish is a seasonal breeder which breeds during the rainy season, July-August (Joy et al., 2000). In captivity, the male brooder needs to be sacrificed to obtain milt while in the natural environment, this fish breeds easily without any complications. The physiology involved in the reproduction of this fish needs to be explored. Hence, the main aim of the present study was to study the structural and functional aspects of RA metabolic gene Cyp26B1 which govern the retinoid signaling. The mRNA expression levels were analysed in different reproductive phases. Furthermore, the mRNA expression was studied after the injection of synthetic GnRH analog $\left(\right.$ Ovatide $\left.^{\mathrm{TM}}\right)$.

\section{Materials and Methods}

\section{Sample and tissue collection}

The wet lab experiment was conducted at the Freshwater Fish Farm, ICAR-CIFE, Powarkeda, Madhya Pradesh, India. Nine fishes were sampled from each stage among the 4 reproductive stages of $C$. magur (i) Preparatory (ii) Mature; (iii) Post Ovatide ${ }^{\mathrm{TM}}$ injection $6 \mathrm{~h}$ and (iv) Post Ovatide ${ }^{\mathrm{TM}}$ injection. For preparatory phase, fished were sampled in the month of February while fishes for spawning phase were collected in August. Ovatide $^{\mathrm{TM}}$ (Hemmo Pharmaceuticals Pvt. Ltd., Mumbai), was injected @ $0.5 \mathrm{ml} \mathrm{kg-1} \mathrm{body}$ weight to male and $1.0 \mathrm{ml} \mathrm{kg-1} \mathrm{(Sharma} \mathrm{et} \mathrm{al.,}$ 2010) to female fishes and sampling was done after $6 \mathrm{~h}$ and $16 \mathrm{~h}$ of injection. In all cases, brain and gonadal tissues were collected, kept in RNAlater ${ }^{\mathrm{TM}}$ (QIAGEN, USA) and stored at 
$-80{ }^{\circ} \mathrm{C}$ until further analysis. Three individuals pool tissue were used to extract total RNA.

\section{RNA extraction and cDNA synthesis}

Total RNA was extracted using Trizol ${ }^{\mathrm{TM}}$ reagent (Invitrogen, USA) and treated with DNase I (Thermo Scientific, USA) to remove the genomic DNA contamination following manufacturer's guidelines. The quality and quantity of the purified total RNA were determined using agarose gel electrophoresis and NanoDrop spectrophotometer (Thermo Scientific, USA). $1 \mu \mathrm{g}$ of DNase treated total RNA was reverse transcribed to cDNA using Oligo dT primer and RevertAid ${ }^{\mathrm{TM}}$ reverse transcriptase First Strand cDNA Synthesis kit (Thermo Scientific, USA) as per the manufacturer's instructions.

\section{Molecular cloning of Cyp26B1 cDNA and RACE amplification}

Primers to amplify partial cDNA of Cyp26B1 were designed using gene runner primer designing tool and synthesized commercially by Eurofins Genomics India Pvt Ltd, India. PCR amplification was performed in a 96-well Takara PCR System (Takara, Japan) with a total volume of $25 \mu \mathrm{L}$ containing $2.5 \mu \mathrm{L}$ of $10 \times$ Taq buffer, $0.5 \mu \mathrm{L}$ of $10 \mathrm{mM}$ each dNTP mix, $2.5 \mu \mathrm{L}$ of $25 \mathrm{mM} \mathrm{MgCl}_{2}, 1 \mu \mathrm{L}$ each of sense and antisense primers (10 pmol), $1 \mu \mathrm{L}$ of cDNA (500ng), $0.25 \mu \mathrm{L}$ of $5 \mathrm{U} / \mu \mathrm{L}$ Taq DNA polymerase and $16.25 \mu \mathrm{L}$ of nuclease-free water. The annealing temperature of each primer set was optimized by touch-down as well as gradient PCR.

The partial cDNA fragments of 504 bp was obtained and eluted from the gel. The eluted PCR product was cloned into pTZ57R/T vector (Thermo Scientific, USA), sequenced and confirmed by BLASTn similarity search. After partial cDNA amplification, genespecific primers (Table 1) for $3^{\prime}$ and $5^{\prime}$ RACE
(Rapid Amplification of Complementary DNA Ends) PCR were designed from the identified partial sequence as per the guidelines provided with the RACE-PCR kit (Clontech, Japan). The reaction was carried out for both $3^{\prime}$ and $5^{\prime}$ ends to obtain the full-length cDNA sequence of the genes comprising of the open reading frame (ORF), 3' and 5' untranslated (UTR) regions. The desired PCR products were purified, cloned and sequenced. The sequences were confirmed by BLASTn software (http://www.ncbi. nlm.nih.gov/blast).

\section{Amino acid sequence analysis and ORF prediction}

The open reading frame (ORF) of the fulllength cDNA sequence obtained through RACE-PCR was determined using NCBI ORFfinder tool (https://www.ncbi.nlm.nih. gov/orffinder/). The amino acid sequence of the coding region was deduced using Gene Runner and conserved domains were identified by NCBI Conserved Domain search tool (https://www.ncbi.nlm.nih.gov/Structure/ cdd/wrpsb.cgi).

\section{Phylogenetic analysis}

The deduced amino acid sequences of the Cyp26B1 from $C$. magur (Indian magur), $I$. punctatus (Channel catfish), D. rerio (Zebrafish), C. carpio (Common carp), Tachysurus fulvidraco (Yellowhead catfish), Silurus meridionalis (Chinese large-mouth catfish), Homo sapiens (human), Mus musculus (Mouse), Ovis aries (Sheep) and Bos taurus (Cattle) were subjected to multiple sequence alignment analysis using CLC Genomics Workbench 9 program software (QIAGEN, USA). The sequence alignment obtained was used to construct a Neighbourjoining tree with 1000 bootstrap replicates using MEGA 7.0 software (Kumar et al., 2016). 
In silico analysis of $C$. magur Cyp26B1 sequence

Physiochemical parameters of the C. magur Cyp26B1 amino acid sequence were analysed using online ProtParam tool at ExPASy (Gasteiger et al., 2005). Secondary structure of amino acid sequence was predicted through online tools like PSIPRED V.3 (McGuffin et al., 2000) and SOPMA (Geourjon et al., 1995), while ProtScale program (Gasteiger et al., 2005) was used to analyze the protein hydropathy profile. SignalP 4.0 software was used to predict the signal peptides (Petersen $e t$ al., 2011).

\section{Homology modeling of Cyp26B1}

The 3D model of C. magur Cyp26B1 was generated using the amino acid sequences of closest homologs for which X-ray crystal structures were available. The solution of NMR structure of Saccharomyces cerevisiae Cyp26B1 (PDB code: c4lxjA) was used as a template. The homology model was generated using Modeller 9v12 software.

\section{Model evaluation}

The stereochemical properties of C. magur Cyp26B1 3D model were analysed through Ramachandran plots from RAMPAGE server (Lovell et al., 2002) and overall quality factor by ERRAT analysis (Colovos et al., 1993). Ramachandran plot tells the percentage of amino acid residues in the favorable and disallowed regions.

The ERRAT program evaluates the statistics of non-bonded interactions between different atom types and plots the value of the error function versus position of a nine-residue sliding window, calculated by a comparison with statistics from highly refined structures. PyMOL 4.4.0 software was used to obtain the superimposition between model and template and also to diagrammatically represent the structures. Ligand binding sites were predicted using I-TASSER program (Roy et al., 2010) and located on predicted protein model using RasMol software (Version 2.7.5.2).

\section{Protein-protein interactions of $C$. magur Cyp26B1}

The interactions of $C$. magur Cyp26B1 protein with other proteins involved in the pathway of steroidogenesis and spermatogenesis were determined using online software STRING (Szklarczyk et al., 2014).

Real time mRNA expression of Cyp26B1 in brain and gonads

The basal mRNA expression analysis of Cyp26B1 mRNA in tissues of C. magur was carried out in LightCycler450 Real-time PCR detection system (Roche, USA). The reactions were performed in $10 \mu \mathrm{L}$ reaction mix volume containing $5 \mu \mathrm{L}$ of $2 \times$ Maxima $^{\mathrm{TM}}$ SYBR Green qPCR master mix (Thermo Scientific, USA), $0.5 \mu \mathrm{L}$ of $(0.3 \mathrm{pM})$ each gene-specific primer (Table 1) and $2 \mu \mathrm{L}$ (20 ng) of cDNA and $2 \mu \mathrm{L}$ of nuclease-free water. The default thermal profile was used for PCR amplification and it consisted of initial denaturation at $95{ }^{\circ} \mathrm{C} / 10 \mathrm{~min}$, followed by 40 cycles of denaturation at $95{ }^{\circ} \mathrm{C} / 20 \mathrm{~s}$, annealing at $64{ }^{\circ} \mathrm{C} / 20 \mathrm{~s}$ and extension at $72{ }^{\circ} \mathrm{C} / 30 \mathrm{~s}$. All reactions were run in triplicate and repeated twice.

Relative expression of genes was determined using comparative $\mathrm{Ct}$ method $\left(2^{-\Delta \mathrm{Ct}}\right.$ ) (Livak et al., 2001). Two putative housekeeping genes $(\mathrm{HKG})$, Elongation factor 1-alpha (EF1 $\alpha)$ and $\beta$-actin were statistically analyzed by the comprehensive algorithm of NormFinder, Bestkeeper and Genorm to assess their transcriptional expression stability. Here, $\beta$ actin was selected as HKG for gene normalization. 


\section{Ethics statement}

The guidelines of the CPCSEA (Committee for the Purpose of Control and Supervision of Experiments on Animals), Ministry of Environment and Forests (Animal Welfare Division), Government of India on care and use of animals in scientific research were followed to care and rear the animals used in the present study. The study was approved by the Board of studies and authorities of ICARCentral Institute of Fisheries Education (ICAR-CIFE), Mumbai-61.

\section{Statistical analysis}

The one-way analysis of variance (ANOVA) of statistical package SPSS 17.0 (USA) was used to test the statistical significance of differences in mRNA transcript levels. $\mathrm{P}<$ 0.05 was considered as statistically significant. The results were expressed as mean \pm SEM (bars).

\section{Results and Discussion}

\section{Molecular cloning of C. magur Cyp26B1 gene}

The partial cDNA fragment of Cyp26B1 (545 bp) was cloned from $C$. magur testis. The fulllength cDNA fragment of 1782 bp (ORF 1533 bp) was obtained by 5,/3' RACE-PCR technique. The ORF of $C$. magur Cyp26B1 gene encoded a putative protein of 511 amino acids. The sequence obtained in the present study was submitted to NCBI GenBank (Accession number: LC365786).

\section{Physiochemical properties and secondary structure analysis of Cyp26B1 protein}

The C. magur Cyp26B1 protein was shown to have apparent molecular weight (MW) of 57241.19 Da with pI of 8.78. The secondary structure of $C$. magur Cyp26B1 predicted by
PSIPRED server showed the presence of $17 \alpha$ helices, 27 coils and $10 \beta$-sheets in the protein as shown in Figure 1. The structural percentage of amino acids of Cyp26B1 predicted by SOPMA software revealed that 246 amino acids (48.14\%) have an alpha helix, 70 (13.70\%) have extended strand, 41 $(8.02 \%)$ have a beta turn, and 154 amino acids $(30.14 \%)$ have random coil structures. $C$. magur Cyp26B1 protein exhibited 31 serine (Ser), 10 threonine (Thr), and 5 tyrosine (Tyr) phosphorylation sites that were uniformly distributed throughout the polypeptide chain as predicted by NetPhos 3.1 Server. As the Cyp26B1 belongs to P450 superfamily which is a large family of haem-thiolate proteins involved in the oxidative degradation of various compounds. They are particularly well known for their role in the degradation of environmental toxins and mutagens. CDD search revealed the presence of four conserved motifs (CR1-CR4) and a conserved hemebinding domain in all members of the P450 superfamily including Cyp26B1 (Fig. 2).

\section{Signal peptide analysis of Cyp26B1 protein}

The signal peptide of the $C$. magur Cyp26B1 protein as determined by SignalP 4.1 server by keeping D-cutoff value as sensitive (0.34) is shown in figure 3 . The comparison was made among signal peptide graphs of Clarias magur, Danio rerio (a model fish) and Ictalurus punctatus (closely related). All the five indexes scores of $C$. magur proteins ( $\max$ $\mathrm{C}$, max $\mathrm{Y}$, max S, mean S, and mean D) were more similar to the score of I. punctatus and less to the $D$. rerio. The D-score (Discrimination score) is the weighted average of the mean $\mathrm{S}$ and the max $\mathrm{Y}$ scores, this is the score mainly used to discriminate signal peptides from non-signal peptides (Petersen et al., 2011). In case of Cyp26B1 protein the D value (Discrimination score) was more (0.453) than the corresponding cut-off value. Thus, Cyp26B1 showed the presence of signal 
peptide from 1-11 residue position confirming its secretory nature.

\section{Sequence and phylogenetic analysis}

Sequencing result of Cyp26B1 was analyzed using BLAST tool at NCBI for similarity search. The deduced amino acid sequence of C. magur Cyp26B1 deduced amino acid revealed $76 \%, 91 \%$ and $96 \%$ identity with human, zebrafish and channel catfish sequences, respectively. Multiple sequence alignment of $C$. magur deduced amino acid sequence of Cyp26B1 with sequences from other fish species showed well-conserved regions across the sequences (Fig. 2). The catalytic domains of Cyp26B1 protein were found to be highly conserved across all the species used for multiple alignment analysis. The identity level of $C$. magur Cyp26B1 amino acid sequence with other species is presented in figure 4. The Neighbour-joining tree for Cyp26B1 was prepared which differentiated the closely related species in separate clades. The catfishes formed one cluster while cyprinids formed a separate group (Fig. 5). Bovine species grouped in to a single cluster while human formed sister group. Cyp26B1 of C. magur was closely related to Chinese large-mouth catfish and channel catfish followed by cyprinids. This finding is consistent with the classification and evolutionary status of these species.

\section{Hydropathy analysis of the Cyp26B1 protein}

The hydropathy profile of the Cyp26B1 protein was determined by ProtScale program which demonstrated that the aspartic acid (D) at residue position 423 of the polypeptide chain exhibited the highest hydrophily (hydrophobic parameter: -3.189) whereas valine (V) at residue position 22 showed the highest hydrophobicity (hydrophobic parameter: 2.822). In Cyp26B1 protein hydropathy graph, the hydrophilic area was also greater than hydrophobic area (Fig. 6). Therefore, the whole Cyp26B1 peptide chain showed hydrophilic character.

\section{D structure prediction and analysis}

Since no PDB file has been reported for Cyp26B1 in human so NMR structure of Saccharomyces cerevisiae Cyp26B1 protein (PDB code: $c 41 x j A$ ) with maximum sequence identity was considered as best hits and used as template to generate 3D model. Pymol software was used to obtain the final 3D ribbon structure of Cyp26B1 PDB sequence obtained from the modeler software (Fig. 7). The ligand binding sites of Cyp26B1 protein were valine at positions 115, 367 and 478; leucine at positions 130, 293, 361, 441 and 445; alanine at positions 131, 193, 296, 297, 304 and 446; histidine at position 138; arginine at positions 142, 372 and 438; phenylalanine at positions 149 and 433; threonine at position 300 ; proline at positions 366, 432 and 477; glycine at positions 370, 434 and 442; isoleucine at position 395 and cysteine at position 440 (Fig. 8).

The overall structural similarity between the C. magur Cyp26B1 protein model with its ortholog (2VE3) from cyanobacteria is shown as backbone superposition with RMS value of 4.68 (Fig. 9). Ramachandran analysis of $C$. magur Cyp26B1 3D model revealed that $94.3 \%$ of the residues are in the most favored regions while $4.2 \%$ are in the additional allowed region (Fig. 10). The data figure indicated that the 3D model generated were highly stable. The overall quality factors of modelled C. magur Cyp26B1 protein in ERRAT analysis was $56.198 \%$ (Fig. 11).

\section{Protein-protein interactions of Cyp26B1}

The protein-protein interactions of Cyp26B1 protein with that of other proteins is presented in figure 12. 
Table.1 Primers used in the study

\begin{tabular}{|l|l|l|}
\hline Primer name & Sequence $\left.\mathbf{( 5}^{\prime} \mathbf{-} \mathbf{3}^{\prime}\right)$ & Usage \\
\hline Cyp26B1F & CGTGCCACTGGTTGGTTCAG & Partial cDNA amplification \\
\hline Cyp26B1R & ATGGCAGGTCAATGGGCAAT & Partial cDNA amplification \\
\hline GSP1 3' & GAGGAACTGCGCAACTGTGGCCTTTTGC & 3' RACE for Cyp26B1 \\
\hline GSP2 3' & CTGGCCACGCTTTTCCTTAAGCTGTTGG & 3' RACE for Cyp26B1 \\
\hline GSP1 5' & GGAGCCTTTTGGCATGGGCAACTTGC & 5' RACE for Cyp26B1 \\
\hline GSP2 5' & CCACAGCTGCTGAGACACGGCGATCAGG & 5' RACE for Cyp26B1 \\
\hline Cyp26B1F_qRT & CCCCAGAGCACCAGCACTCTTCTA & Real time PCR \\
\hline Cyp26B1R_qRT & TGCTGGATCTTGGGCAAGTAGCTC & Real time PCR \\
\hline B_actinF & GCCGAGAGGGAAATTGTCCGTG & Internal Control \\
\hline B_actinR & GCCAATGGTGATGACCTGTCCG & Internal Control \\
\hline
\end{tabular}

Fig.1 Secondary structure of $C$. magur Cyp26B1 predicted by PSIPRED server. The $\alpha$-helices, coils and $\beta$-sheets are highlighted in pink, black and yellow, respectively

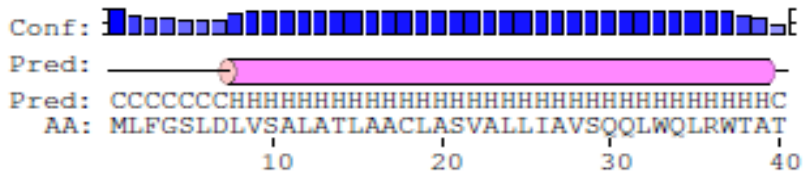

Conf: Pred:

Pred: CCCCCCCCCCCCCCCCCCCCCCCCCCCCCCCCHHHHHOC A.A: RDKNCKLPMP,KGSMGEP IVGETCHWLVQGAGF HSSRRQKY 6070 80

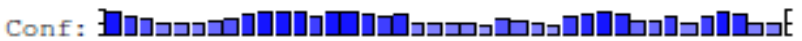

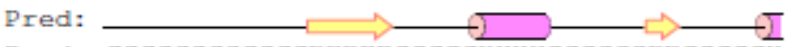

Pred: CCCCCCCCCCCCEEEEECCCCCHHHHCCCCCCEECCCCCH AA: GNVEKTHLLGRPVIRVTGAENVRKVLMGEHSLVSVDWPQS $90 \quad 100 \quad 110 \quad 120$

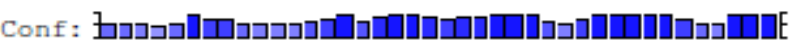

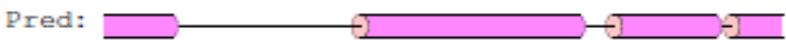

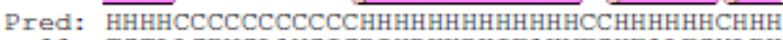
A.A: TSTLLGPNSL.ANS IGDI HRKKRKIFAKVFSHEALESYLPK $\begin{array}{llll}130 & 140 & 150 & 160\end{array}$

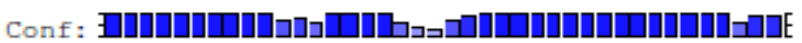
Pred:

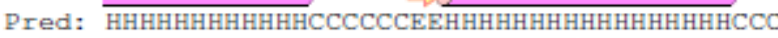
A.A: IQQVIQETLRVWSSNPKP INVYRESQYLSFQMAIRVLLGF $\begin{array}{llll}170 & 180 & 190 & 200\end{array}$

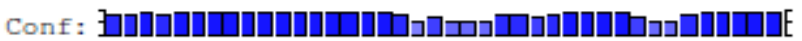

Pred: —

Pred: CCCHHHHHHHHHHHHHHHCCCCCCCCCCCCCCCHHHHHHH AA: RISDEEMHFLFHTFQDFVDNVFSLP IDLPF SGYRKGIRAR $\begin{array}{llll}1 & 1 & 1 & 1 \\ 210 & 220 & 230 & 240\end{array}$

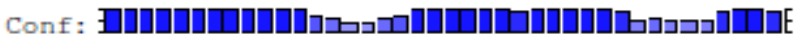

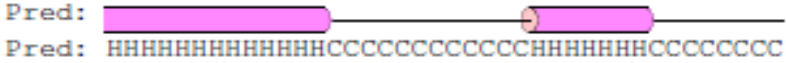
AA: DTLQKAIEKAIREKPLCTQGKDYSDALDVLLESAKENGTE

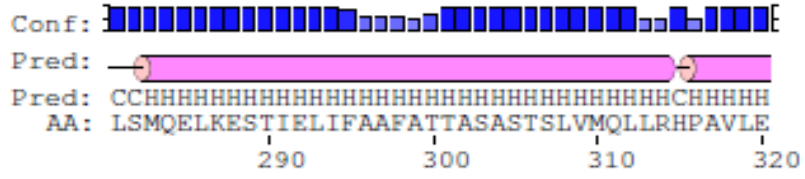

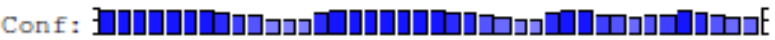

Pred:

Pred: HHHHHHHHHHHHCCCCCCCCCCCHHHCCCCCCHHHHHHHH AA: KLREELRNCGLLHDGCLCQGELRLDNICSLKYLDCVIKEV $\begin{array}{llll}330 & 3 & 3 & 3 \\ 3 & & 360\end{array}$

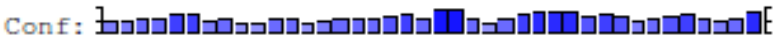
Pred: $\longrightarrow \longrightarrow \longrightarrow \longrightarrow$

Pred: HCCCCCCCCCCCCEEEEEEECCEECCCCCEEEECCCCCCC AA: LRLYAPVSGGYRTAMQTEEL,DGVOIPKGWSYMYSIRDTHD $\begin{array}{llll}370 & 380 & 390 & 400\end{array}$

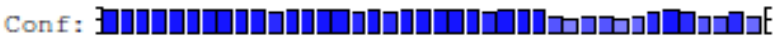

Pred:

Pred: CCCCCCCCCCCCCCCCCCCCCCCCCCCCCEEECCCCCCCC

AA: TSAVFKDVAAFDPDRFSAERSEDREGRFHYLPFGGGVRSC $\begin{array}{llll}410 & 420 & 430\end{array}$

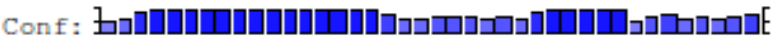

Pred:

Pred: CCHHHHHHHHHHHHHHHHCCCCCEECCCCCOCCEECCCCC

AA : LGKOLATLFLKLLAIELAGGSRFELATRTFPRLISVPVVH $\begin{array}{llll}450 & 460 & 4 & \\ 4 & 780\end{array}$

Conf: :

Pred:

Pred: CCCCCCEEEEECCCCCCCCCCHHHHHHCCCC

AA: PTDGLRVKFEGLDSNQNQIMSKTDEMLGATV

$$
\begin{array}{lll}
490 & 1 & 1 \\
400 & 510
\end{array}
$$

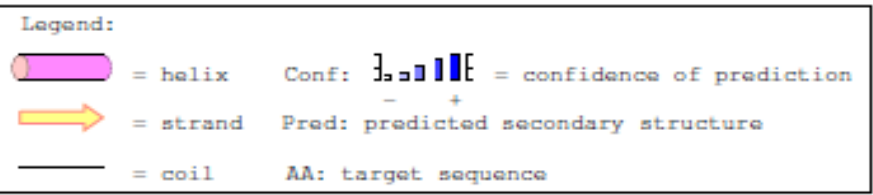


Fig.2 Conserved amino acid sequences of the Cyp26B1 proteins across different vertebrates. Amino acid sequences encoding the Cyp26B1 proteins were aligned using the Clustal W algorithm of the CLC Genomics Workbench 9. The bars below indicate the conserved motifs in different vertebrates. The black arrows represent the conserved domains and heme binding motif of Cyp26B1 protein. The amino acid sequences of I. punctatus (XP_017327166.1), S. meridionalis (ALX81663.1), D. rerio (NP_997831.1), C. carpio (XP_018963264.1), H. sapiens (NP_063938.1), B. Taurus (NP_001179722.1), O. aries (XP_004006116.1) and M. musculus

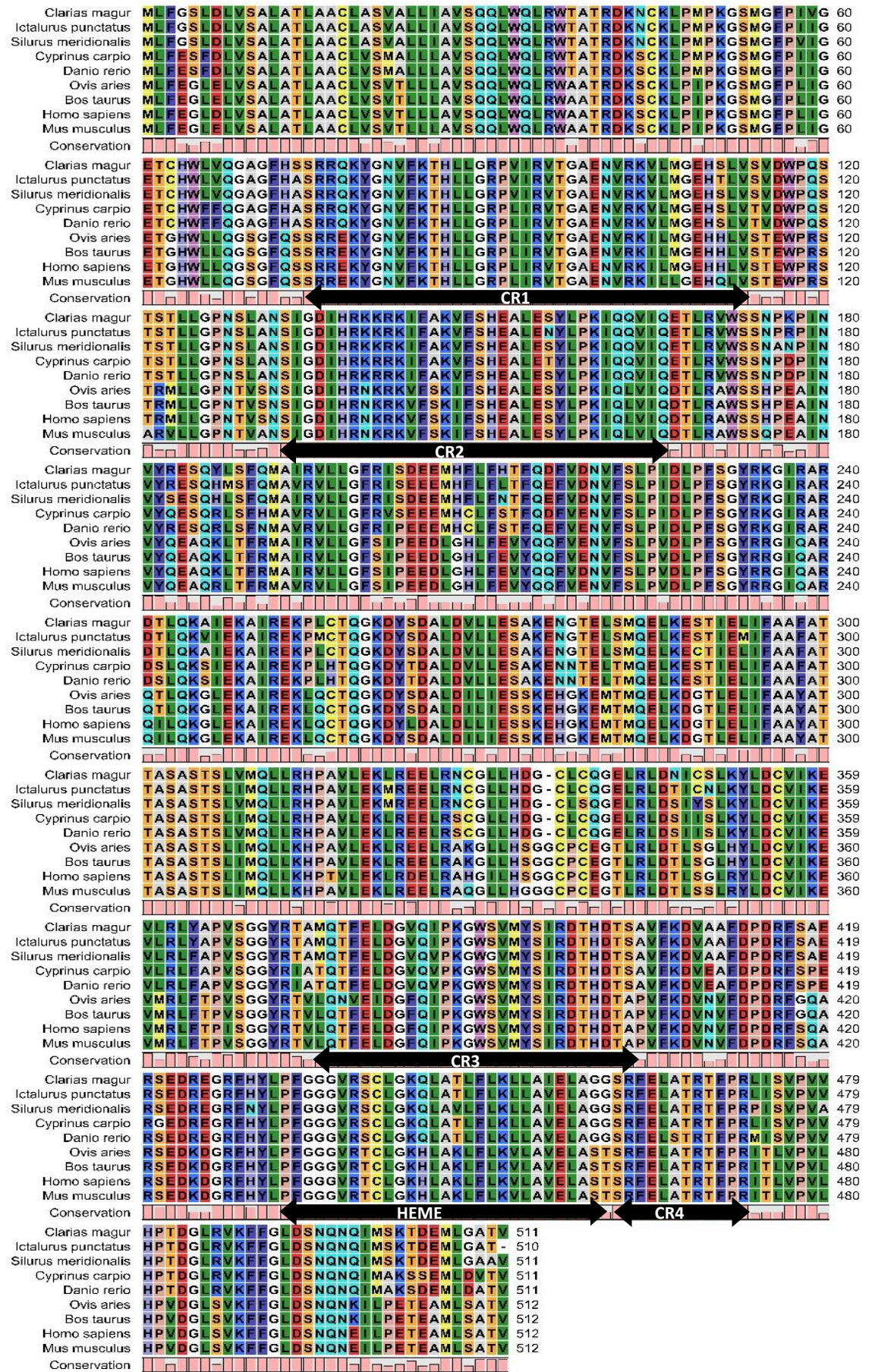


Fig.3 The predicted signal peptide of C. magur (A) D. rerio (B) and I. punctatus (C) Cyp26B1 proteins. The signal peptide was predicted by the Signal P 4. 1 online tool
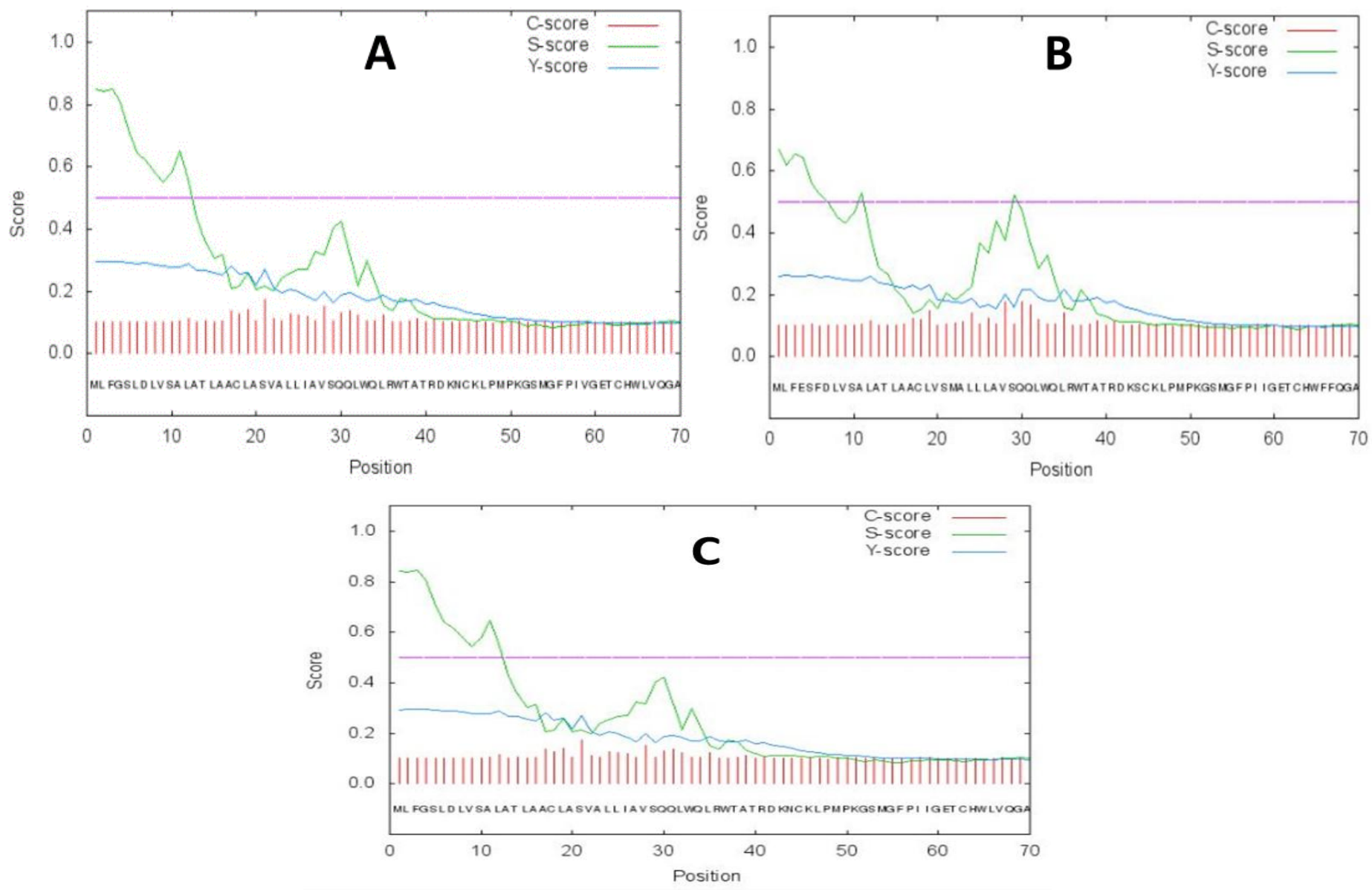

Fig.4 Graph showing percentage similarity of $C$. magur Cyp26B1 amino acid sequence with other species including fishes and mammals

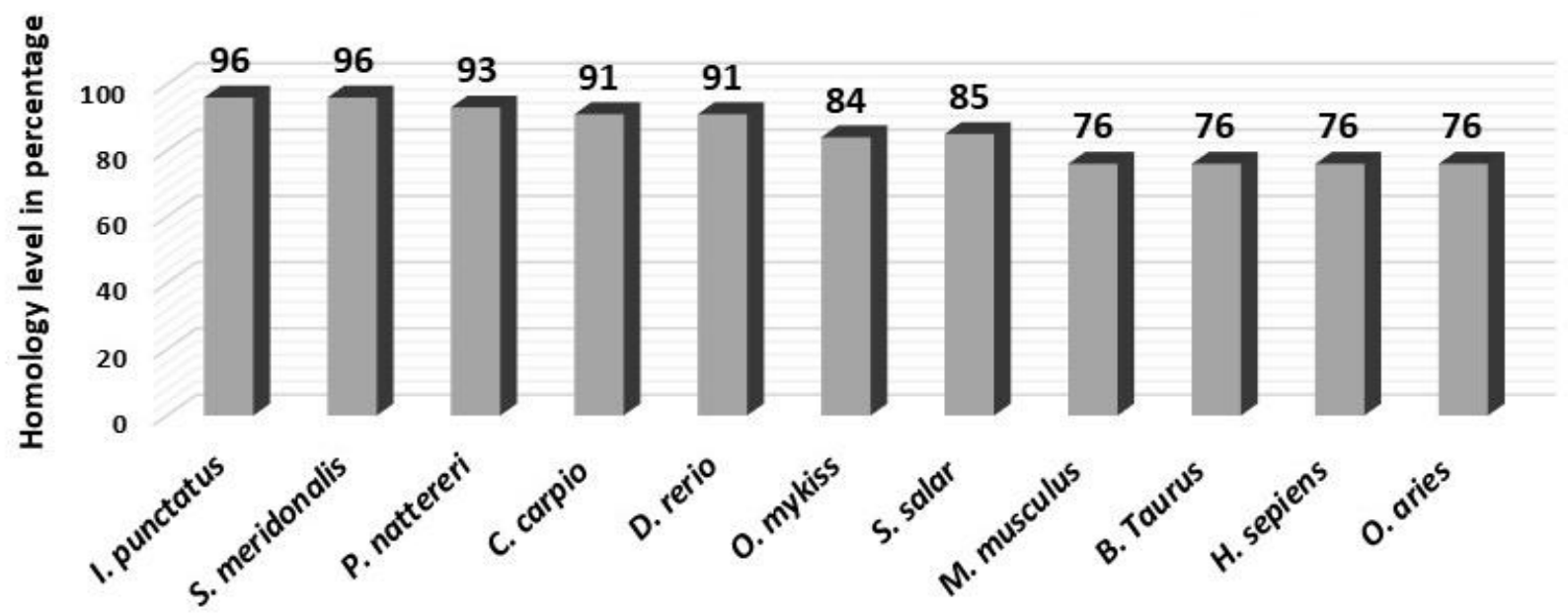


Fig.5 Phylogenetic analysis of C. magur Cyp26B1

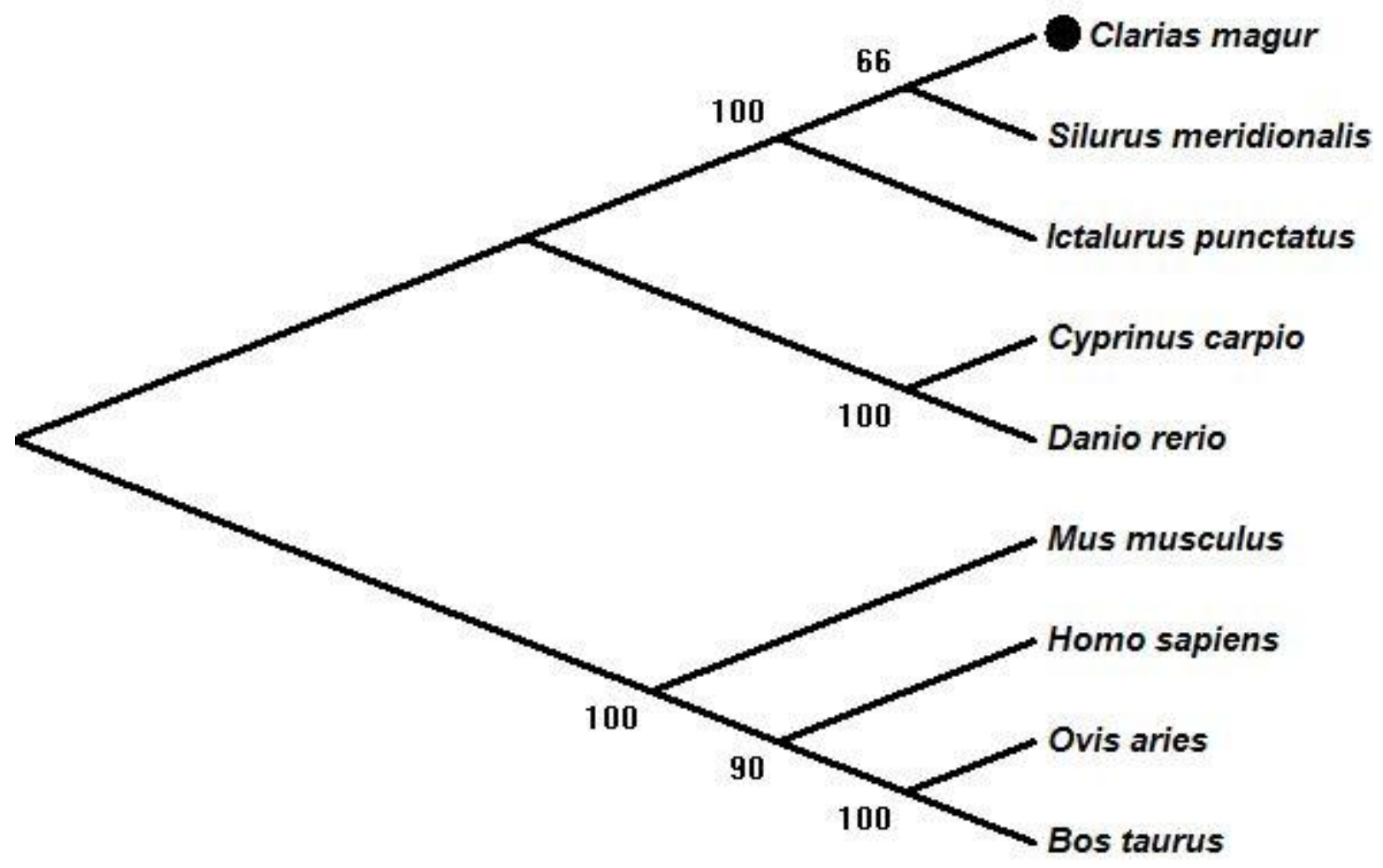

Fig.6 The hydropathy profile of C. magur Cyp26B1 protein

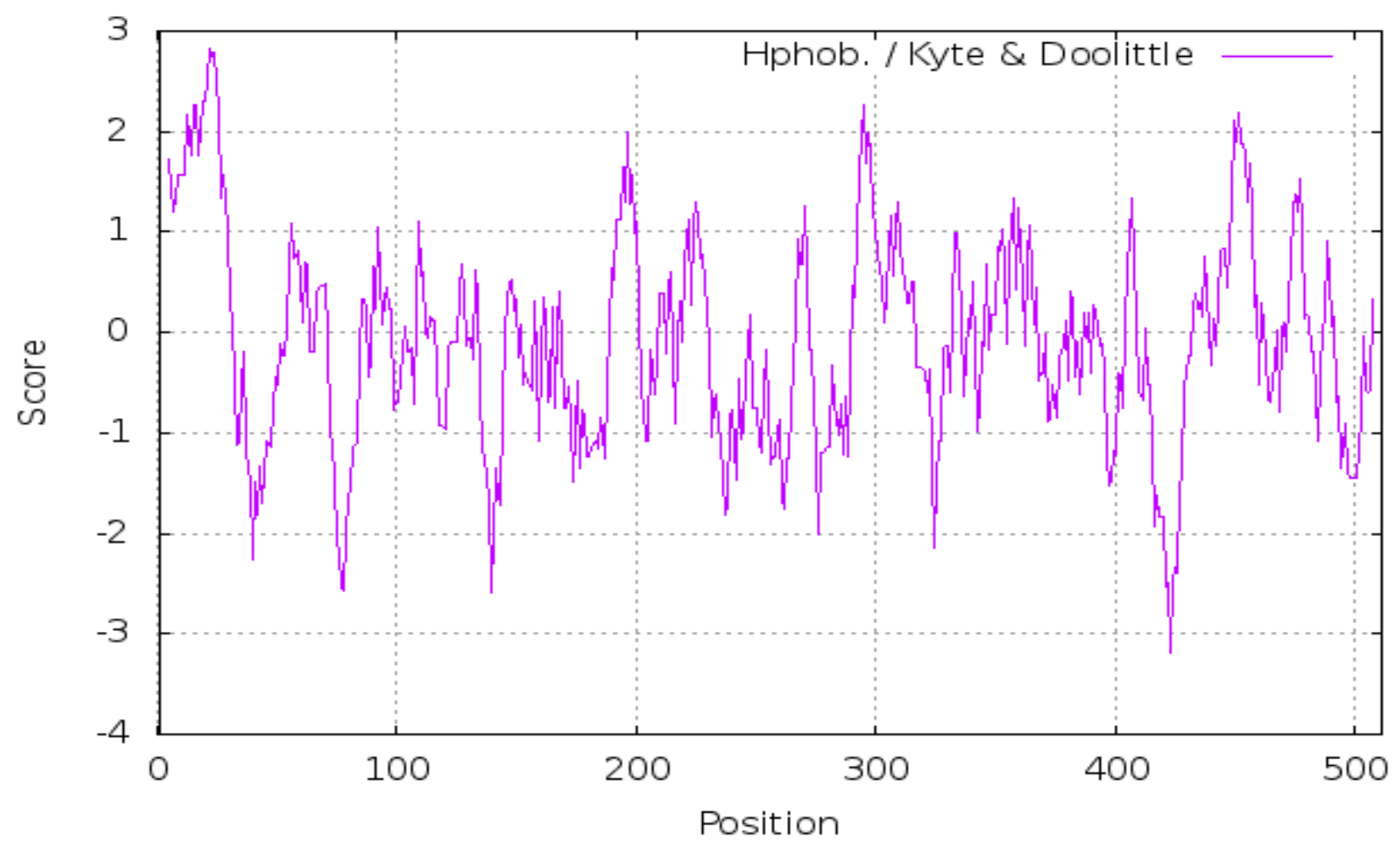


Fig.7 Ribbon diagram showing the tertiary structure of C. magur Cyp26B1 (B) protein. Alpha helices are shown in red colour, beta sheets in yellow colour, and coils are shown in green colour

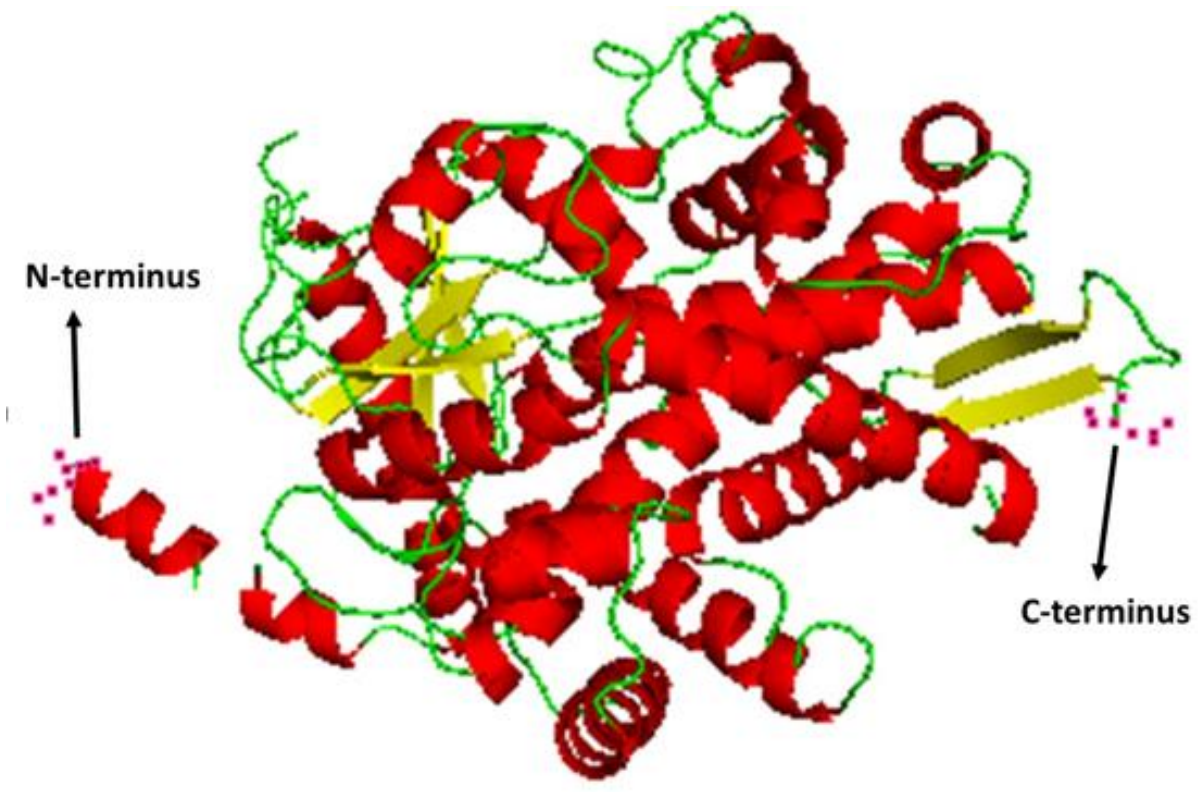

Fig.8 Stick diagram of Cyp26B1 protein. The red colour sticks of the structure are showing the ligand binding sites

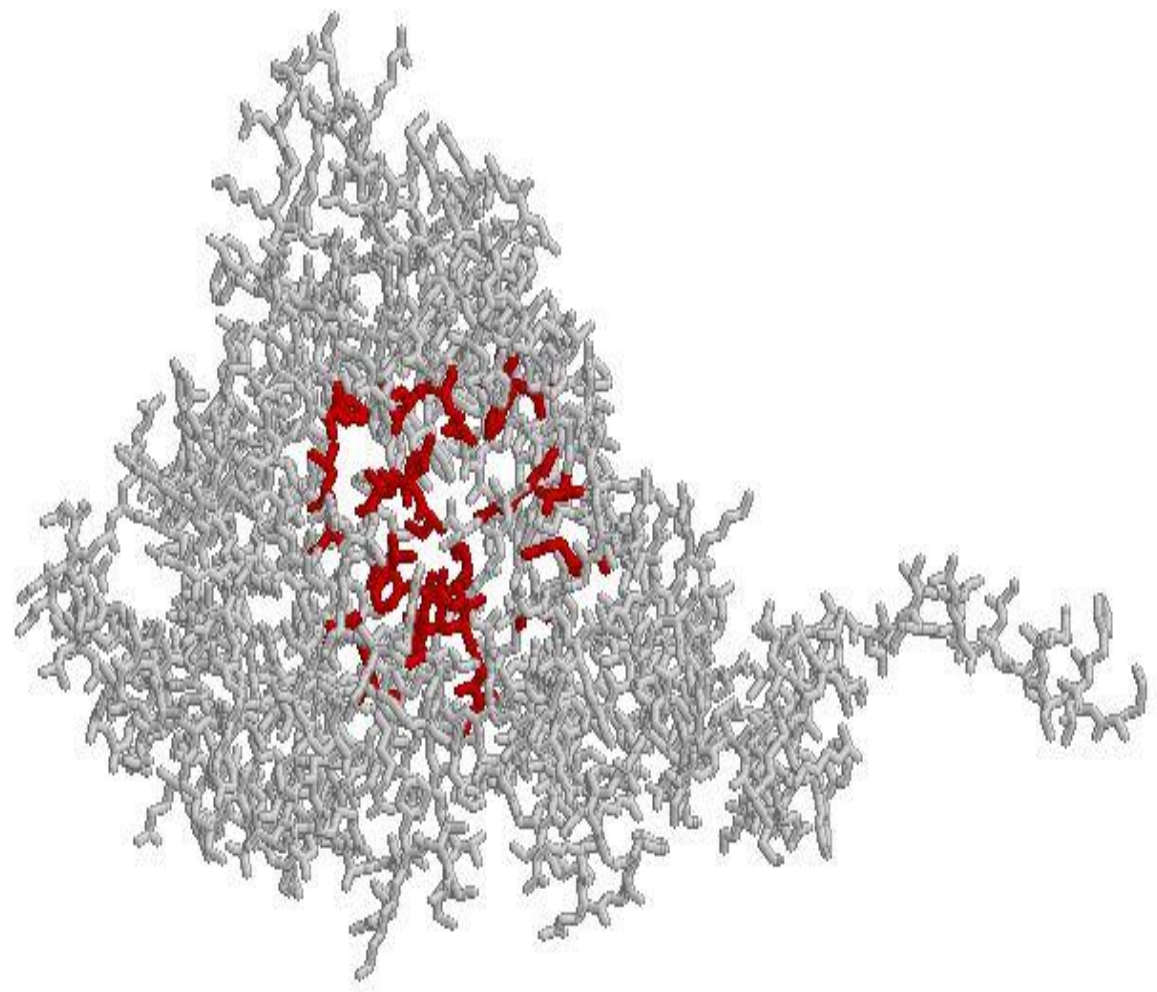


Fig.9 Superimposition of modelled Cyp26B1 protein of C. magur (Red, yellow and green) with template 2VE3 (Cytochrome P450) (blue, violet and orange). Red and Blue indicate helices, yellow and violet indicate sheets and green and orange indicate coils

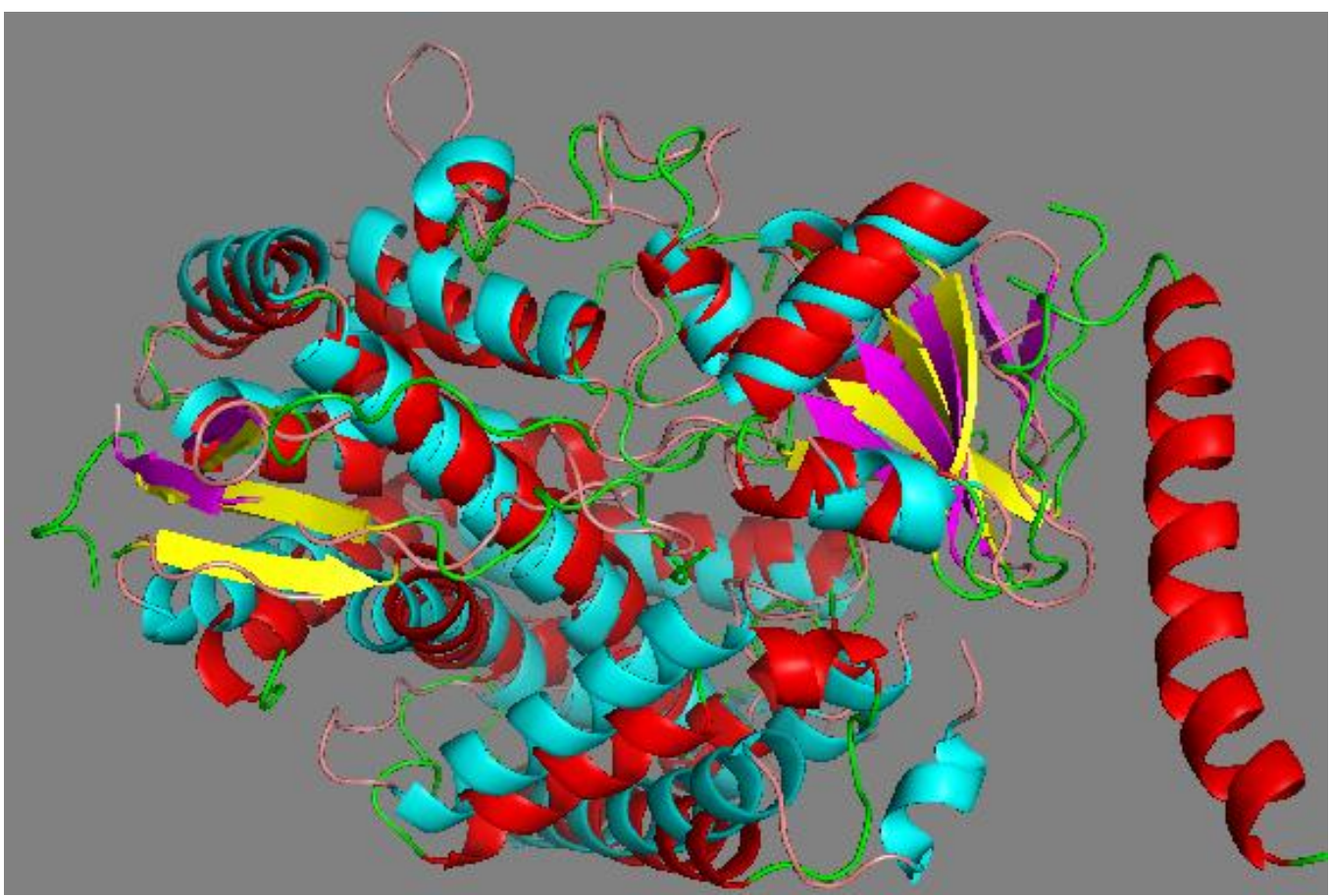

Fig.10 Ramachandran plot (RAMPAGE) of $C$. magur Cyp26B1 showing the dihedral angles Psi and Phi of amino acid residues. The residues which lie in most favoured regions are shown in blue curves and the residues which lie in additional allowed regions are in yellow curves

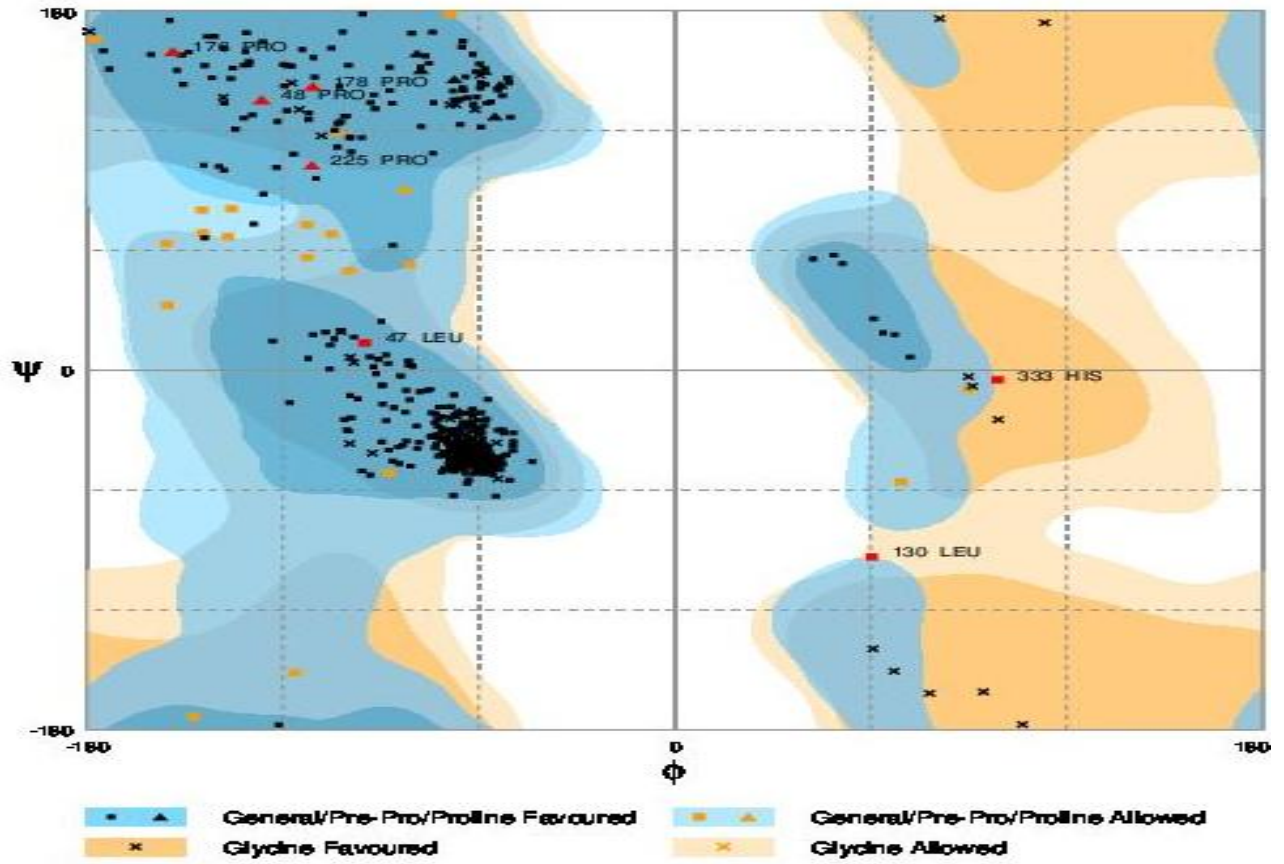


Fig.11 ERRAT plot analysis of modelled C. magur Cyp26ACyp26B1 (B) proteins

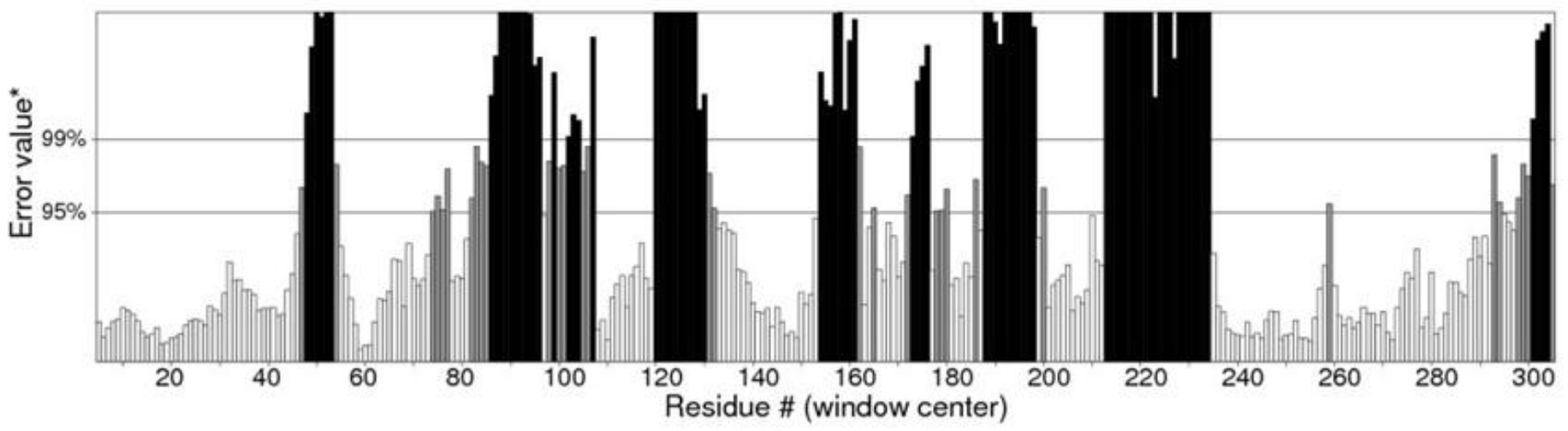

Fig.12 Interaction networks of C. magur Cyp26B1 with other proteins as predicted by STRING

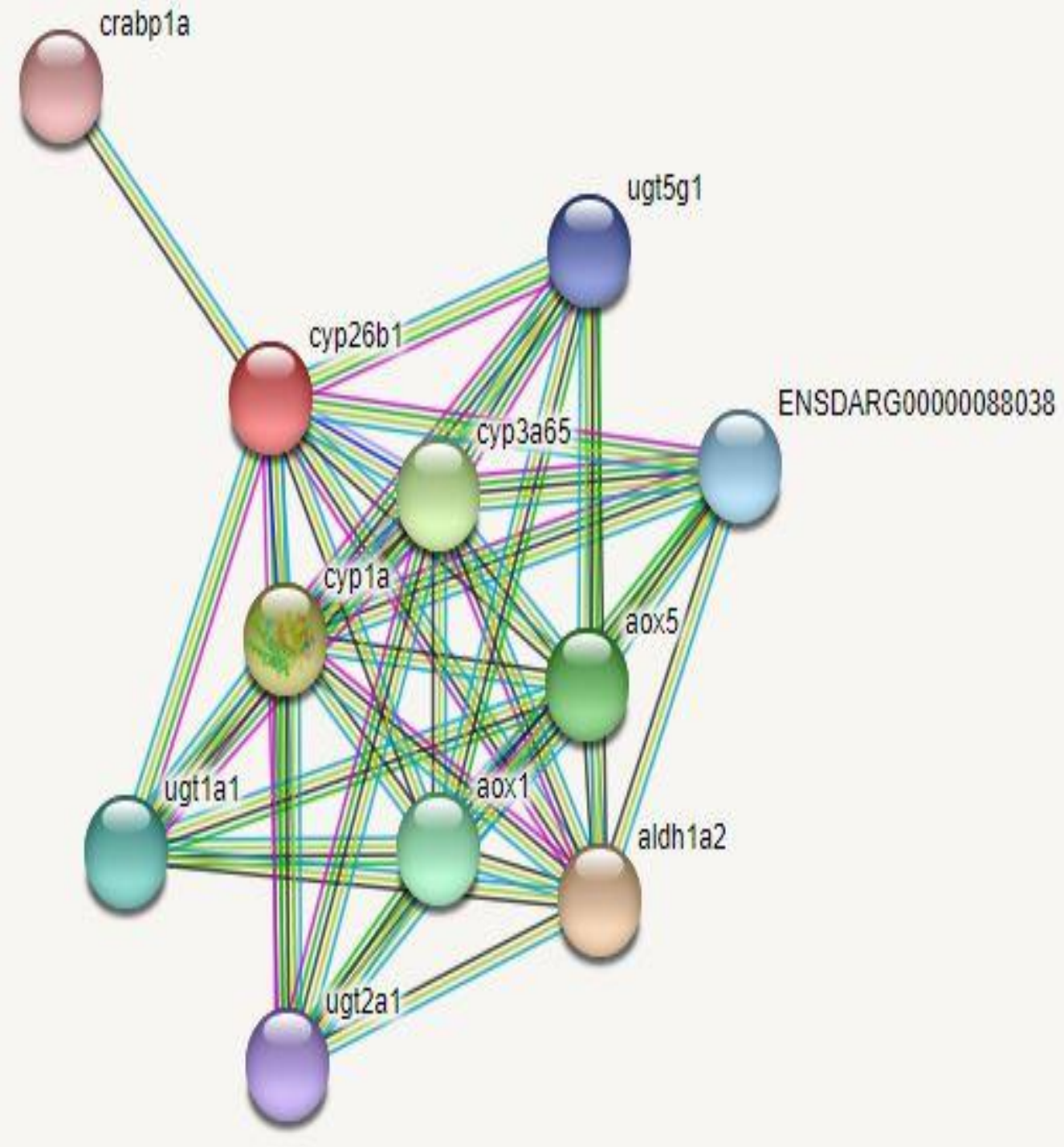


Fig.13 qRT-PCR analysis of Cyp26B1 mRNA expression in ovary and brain of different maturation stages of $C$. magur female. The relative expression of Cyp26B1 normalized with $\beta$ actin was calculated using comparative $\mathrm{Ct}$ method. Data for real-time PCR were expressed as

$$
\text { mean } \pm \text { S.E.M }(n=3)
$$

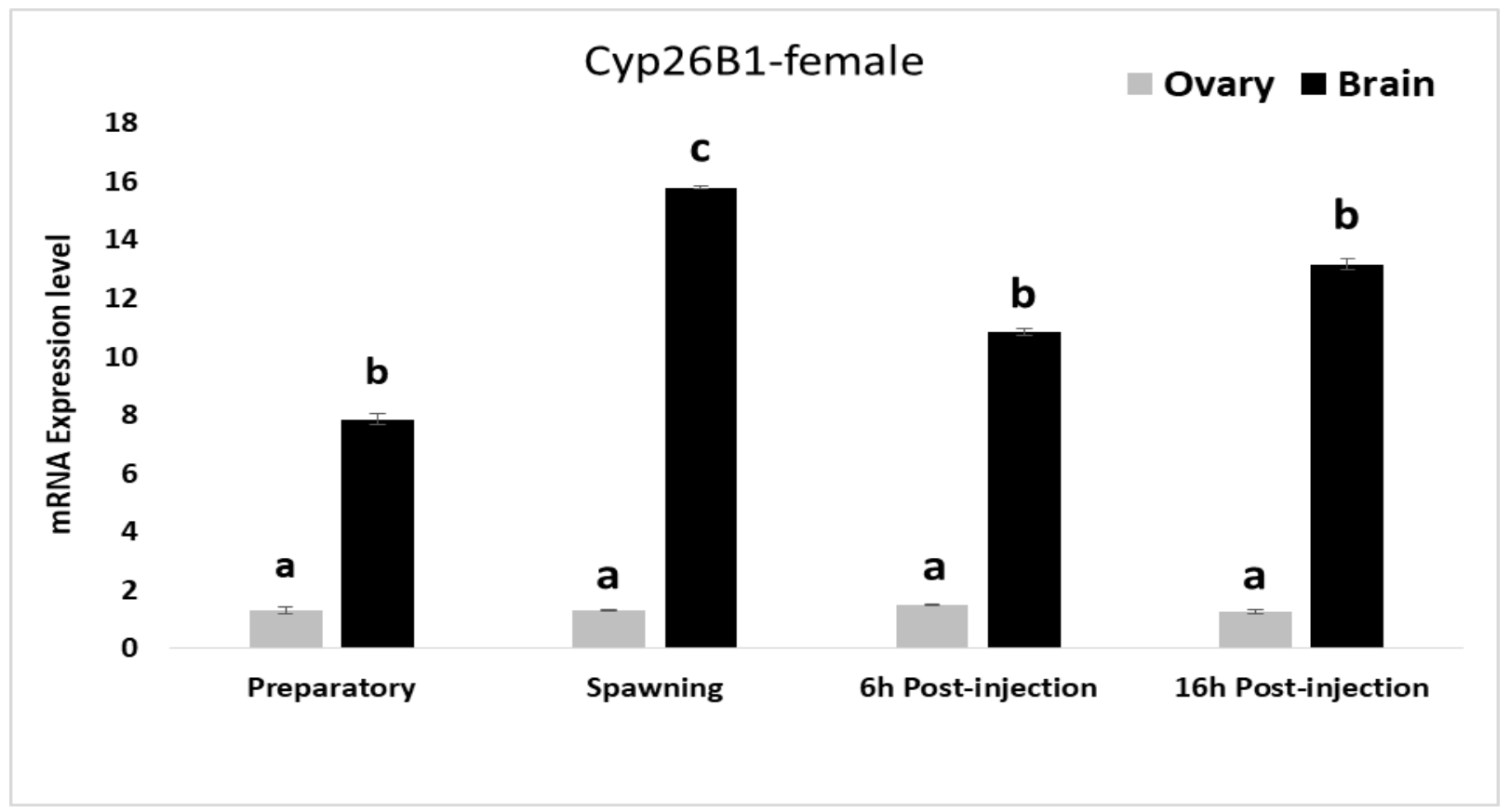

Fig.14 qRT-PCR analysis of Cyp26B1 mRNA expression in testis and brain of different maturation stages of $C$. magur male. The relative expression of Cyp26B1 normalized with $\beta$ actin was calculated using comparative $\mathrm{Ct}$ method. Data for real-time PCR were expressed as mean \pm S.E.M $(n=3)$

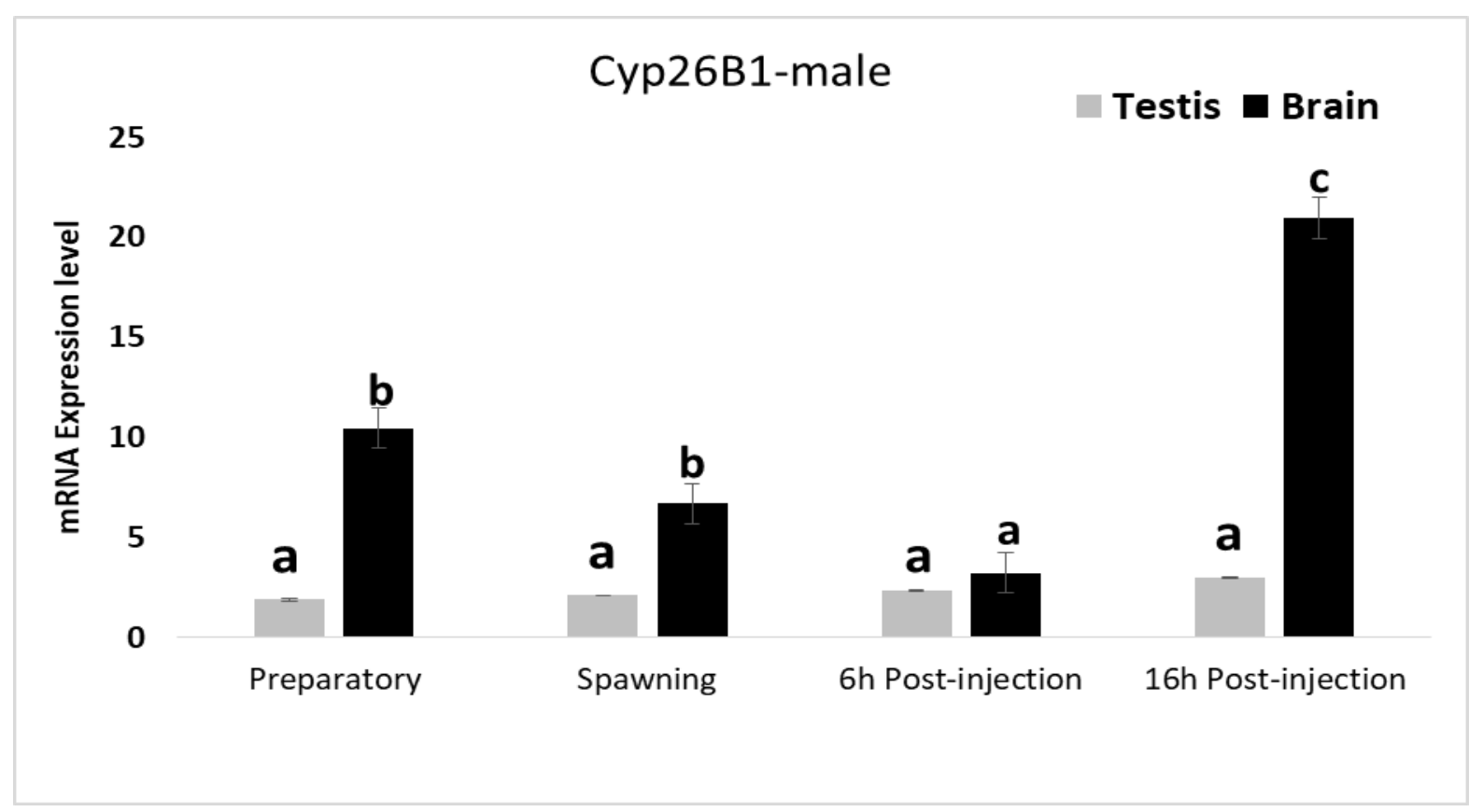


Supp. Fig.1 Supplementary file of string Cyp26B1

Nodes:

Network nodes represent proteins

splice isoforms or post-translational modifications are collapsed, i.e. each node represents all the proteins produced by a single, protein-coding gene locus.
Node Color

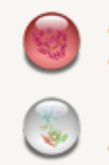

colored nodes: query proteins and first shell of interactors

white nodes:

second shell of interactors
Node Content

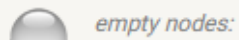

proteins of unknown 3D structure

filled nodes:

some $3 D$ structure is known or predicted

Edges:

Edges represent protein-protein associations

associations are meant to be specific and meaningful, i.e. proteins jointly contribute to a shared function; this does not necessarily mean they are physically binding each other.

\section{Known Interactions}

C-O from curated databases

C-O experimentally determined

Predicted Interactions

○-○ gene neighborhood

e-९ gene fusions

○-○ gene co-occurrence
Others

e- - textmining

○-○ co-expression

○-○ protein homology

Your Input:

Cytochrome P450, family 26, subfamily b, polypeptide 1; Involved in the metabolism of retinoic acid (RA),

- cyp26b1 rendering this classical morphogen inactive through oxidation. Appears to be involved in the inactivation of all-trans-retinoic acid (RA). Plays a role in skeletal development (511 aa)

Predicted Functional Partners:

\begin{tabular}{|ll}
\hline aldh1a2 & Aldehyde dehydrogenase 1 family, member A2 (518 aa) \\
\hline cyp1a & Cytochrome P450, family 1, subfamily A; Cytochromes P450 are a group of heme-thiolate monooxygenases (5... \\
\hline cyp3a65 & Cytochrome P450, family 3, subfamily A, polypeptide 65 (518 aa) \\
\hline aox5 & Aldehyde oxidase 3 (1241 aa) \\
\hline aox1 & Aldehyde oxidase 1 (1338 aa) \\
\hline ugt1a1 & UDP glucuronosyltransferase 1 family a, b (536 aa) \\
\hline ENSDARG00000088038 UDP glucuronosyltransferase 2 family, polypeptide B6 (258 aa) \\
\hline ugt5g1 & UDP glucuronosyltransferase 5 family, polypeptide G1 (528 aa) \\
\hline ugt2a1 & UDP glucuronosyltransferase 2 family, polypeptide A4 (543 aa) \\
\hline
\end{tabular}

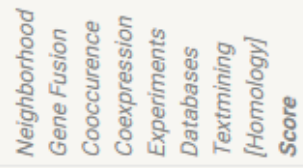

- 0.962

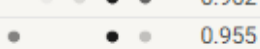

- $\bullet 0.928$

- 0.922

- 0.922

- 0.916

- $\quad 0.912$

- $\quad 0.912$

- $\quad 0.912$

- $\quad 0.906$
The interaction revealed that Cyp26B1 protein has a strong association with aldehyde dehydrogenase 1 family, member A2 (aldh1a2) followed cytochrome P450 gene family (cyp1a and cyp3a65) with a confidence score of $0.962,0.955$ and 0.928 respectively (see supplementary file).

\section{Expression analysis of C. magur Cyp26B1gene}

The mRNA expression pattern of Cyp26B1 gene in $C$. magur adult male and female fishes was determined through qRT-PCR in brain and gonads at four different maturation stages namely preparatory, spawning (before injection), $6 \mathrm{~h}$ post-Ovatide ${ }^{\mathrm{TM}}$ injection and
$16 \mathrm{~h}$ post-Ovatide ${ }^{\mathrm{TM}}$ injection (post-spawning). The Cyp26B1 gene in female fish was expressed in ovary and brain of all selected stages with significantly higher mRNA expression in the brain. However, no statistically significant differences in mRNA expression were observed in the ovary at various maturation stages (Fig. 13). In the female brain, highest mRNA expression of Cyp26B1 was observed at spawning stage followed by hormone stimulated stages and least at the preparatory stage. Similarly, in case of male fish Cyp26B1 gene showed higher mRNA expression in the brain compared to testis with significantly peak expression at $16 \mathrm{~h}$ post-Ovatide ${ }^{\mathrm{TM}}$ injection stage in brain (Fig. 14). The expression of 
Cyp26B1 observed in testis was very less. We cloned the full-length cDNA sequence of Cyp26B1 (ORF 1533 bp) gene from $C$. magur using 5'/3' RACE-PCR strategy. The fulllength cDNA sequence of Cyp26B1 has also been reported in zebrafish (Zhao et al., 2005). The predicted ORF and deduced amino acid sequence was similar to other fish species like channel catfish (XP_017327166.1), and zebrafish (NP_997831.1). The catalytic active site motifs including heme-binding domain of Cyp26B1 gene and similarity analysis between different vertebrates revealed that these motifs are highly conserved (Fig. 2). Cyp26B1 has a PFGGGVRXCLGKXLAXLF LKLLAXELA heme-binding domain (highlighted in Fig. 2) located at the Cterminal end. The cysteine residue of the active site motif serving as a critical catalytic residue, directly involved in heme-binding and surrounded by several highly conserved amino acids. The present results of Cyp26B1 gene sequence were in agreement with other reports confirming that these motifs are highly conserved in most of the Cyp26 subfamily members (White et al., 1996; White et al., 1997; MacLean et al., 2001; Li et al., 2016).

The phylogenetic analysis of $C$. magur Cyp26B1, with other species, revealed high similarity with $I$. punctatus, D. rerio and other catfishes. The $C$. magur Cyp26B1 showed $76 \%$ similarity with its orthologs from human which is similar to the homology obtaibed in zebrafish (Xi et al., 2015).

The prediction of ligand binding sites in a protein helps to understand its putative function and molecular interaction with other proteins or molecules (Rausell et al., 2010). Many ligand binding sites have been predicted in $C$. magur Cyp26B1 amino acid sequence out of which few have been revealed through homology modeling in human (Shimshoni et al., 2012). This is the first report on the putative ligand binding sites in any catfish species and will greatly help in understanding the molecular mechanism of action of these important proteins in the oxidative metabolism of all-trans-retinoic acid.

The hydropathicity analyzed using the KyteDoolittle algorithm predicted that $C$. magur Cyp26B1 protein is more hydrophobic at $\mathrm{N}$ terminus region due to the presence of a highly hydrophobic region of nonpolar amino acids and is believed to function as a transmembrane signal anchor. Similar kind of hydropathy profile has been observed in its human ortholog by White et al., (1997). Overall the Cyp26B1 protein of $C$. magur is hydrophilic in nature like its orthologs from zebrafish and human (White et al., 1996; White et al., 1997; Zhao et al., 2005). From the RAMPAGE server, the percentage of residues in favored regions of Cyp26B1 obtained from Ramachandran plot were $94.3 \%$ which is in contrast to the earlier report on human (Karlsson et al., 2008).

From the above mentioned background it is clear that RA plays crucial role in the regulation of genes involved in cell proliferation, differentiation and tissue function, hence essential for germ cell development. Though over and under expression of genes involved in the synthesis and degradation of RA resulted into the disturbed embryonic development therefore it is essential to maintain the homeostasis of RA. For mRNA expression analysis of Cyp26B1 in $C$. magur, adult male and female of two maturation stages preparatory and spawning were taken. To see the changes in gene expression after ovatide induction, $6 \mathrm{~h}$ and $16 \mathrm{~h}$ post induction stages were also taken. Study of mRNA expression was done by qRT-PCR. The mRNA expression results of Cyp26B1 in fish ovary were not in contrast to the results of other reports in which they 
found a good expression of Cyp26B1 in the ovary (Zhao et al., 2005). We found very minor expression of Cyp26B1 in ovary of $C$. magur. As the role of RA described in earlier studies, it should be required at the preparatory stage of fish in agreement to this, the present study showed significantly higher mRNA expression of Cyp26B 1 in the brain at spawning and $16 \mathrm{~h}$ post-Ovatide ${ }^{\mathrm{TM}}$ injection stages compared to the preparatory stage in female fish. Lower expression of Cyp26B1 in brain and ovary at preparatory stage precluded degradation of RA which suggested the need of RA at the preparatory stage for the regulation of meiotic initiation. As suggested by Lau et al., 2013, both higher and lower expression of RA resulting from disrupted aldh1a2 and cyp26s expressions are involved in disturbed meiotic entry in gonad. Significantly higher expression of Cyp26B1 at spawning stage might responsible for the depletion of RA. Similarly, the mRNA expression of Cyp26B1 was also very less in testis compared to the brain of male fish. An earlier study on mouse suggested the role of Cyp26 genes in early development (Ray et al., 1997) while in case of $C$. magur, the Cyp26B1 was found to be least expressed at the preparatory stage in testis. The brain of male fish showed the Cyp26B1 expression but decreased gradually from preparatory stage and peak at $16 \mathrm{~h}$ of Ovatide ${ }^{\mathrm{TM}}$ injection stage. This significant observation if studied in detail might give a clue regarding the reproductive dysfunction of males during induced breeding in captivity. The mRNA expression of Cyp26B1 in C. magur needs further study on the controlled expression of Cyp26B1 gene under controlled conditions.

In summary, the present study reports fulllength coding sequence of Cyp26B1 gene from $C$. magur. The sequence was analysed using various bioinformatics tools to predict the structural and functional features. The ligand binding sites predicted in the protein can be used for drug designing in future. The differential mRNA expression analysis of the gene at various maturation stages revealed lowest expression of Cyp26B1 in the ovary and testis compared to brain of both the sexes. Preparatory stage of female brain showed very less expression while spawning stage showed peak expression. To the best of our knowledge, this is the first report of cloning and structural analysis of Cyp26B1 full-length cDNA in Indian catfish.

\section{Acknowledgements}

The authors are thankful to Director, ICARCentral Institute of Fisheries Education, Mumbai, India for providing all the facilities to conduct the present research.

\section{Conflict of interest}

Authors declare that they have no actual or potential conflict of any interests.

\section{References}

Abu-Abed, S., Dollé, P., Metzger, D., Beckett, B., Chambon, P., and Petkovich, M. (2001). The retinoic acidmetabolizing enzyme, CYP26A1, is essential for normal hindbrain patterning, vertebral identity, and development of posterior structures. Genes and development, 15(2): 226240.

Chung, S. S. W., and Wolgemuth, D. J. (2004). Role of retinoid signaling in the regulation of spermatogenesis. Cytogenetic and genome research, 105(2-4): 189-202.

Clagett-Dame, M., and Knutson, D. (2011). Vitamin A in reproduction and development. Nutrients, 3(4): 385-428.

Colovos, C. and Yeates, T.O. (1993). Verification of protein structures: patterns of nonbonded atomic 
interactions. Protein Science, (2): 511519.

Feng, R., Fang, L., Cheng, Y., He, X., Jiang, W., Dong, R., Shi, H., Jiang, D., Sun, L. and Wang, D. (2015). Retinoic acid homeostasis through aldh1a2 and cyp26a1 mediates meiotic entry in Nile tilapia (Oreochromis niloticus). Scientific reports, 5: 10131.

Gasteiger, E., Hoogland, C., Gattiker, A., Duvaud, S. E., Wilkins, M. R., Appel, R. D. and Bairoch, A. (2005). Protein identification and analysis tools on the ExPASy server (pp. 571-607). Humana Press.

Geourjon, C. and Deleage, G. (1995). SOPMA: significant improvements in protein secondary structure prediction by consensus prediction from multiple alignments. Computer applications in the biosciences: CABIOS, 11(6): 681684.

Joy, K. P., Singh, M. S., Senthilkumaran, B. and Goos, H. J. T. (2000). Pituitarygonadal relationship in the catfish Clarias batrachus (L): A study correlating gonadotrophin-II and sex steroid dynamics. Zoological science, 17(3): 395-404.

Karlsson, M., Strid, A., Sirsjö, A., and Eriksson, L. A. (2008). Homology models and molecular modeling of human retinoic acid metabolizing enzymes cytochrome P450 26A1 (CYP26A1) and P450 26B1 (CYP26B1). Journal of chemical theory and computation, 4(6): 1021-1027.

Kumar, S., Stecher, G., and Tamura, K. (2016). MEGA7: Molecular

Evolutionary Genetics Analysis version 7.0 for bigger datasets. Molecular biology and evolution, 33(7): 18701874.

Lau, E. L., Lee, M. F., and Chang, C. F. (2013). Conserved sex-specific timing of meiotic initiation during sex differentiation in the protandrous black porgy Acanthopagrus schlegelii. Biology of reproduction, 88(6): 150-1.

Li, M., Feng, R., Ma, H., Dong, R., Liu, Z., Jiang, W., Tao, W. and Wang, D. (2016). Retinoic acid triggers meiosis initiation via stra8-dependent pathway in Southern catfish, Silurus meridionalis. General and comparative endocrinology, 232: 191-198.

Livak, K. J. and Schmittgen, T. D. (2001). Analysis of relative gene expression data using real-time quantitative PCR and the 2- $\triangle \Delta \mathrm{CT}$ method. Methods, 25(4): 402-408.

MacLean, G., Abu-Abed, S., Dollé, P., Tahayato, A., Chambon, P., and Petkovich, M. (2001). Cloning of a novel retinoic-acid metabolizing cytochrome P450, Cyp26B1, and comparative expression analysis with Cyp26A1 during early murine development. Mechanisms of development, 107(1): 195-201.

MacLean, G., Li, H., Metzger, D., Chambon, P., and Petkovich, M. (2007). Apoptotic extinction of germ cells in testis of Cyp26b1 knockout mice. Endocrinology, 148(10): 4560-4567.

McGuffin, L. J., Bryson, K. and Jones, D. T. (2000). The PSIPRED protein structure prediction server. Bioinformatics, 16(4): 404-405.

Nelson, D.R., Koymans, L., Kamataki, T., Stegeman, J.J., Feyereisen, R., Waxman, D.J., Waterman, M.R., Gotoh, O., Coon, M.J., Estabrook, R.W. and Gunsalus, I.C. (1996). P450 superfamily: update on new sequences, gene mapping, accession numbers and nomenclature. Pharmacogenetics, 6(1): $1-42$.

Petersen, T. N., Brunak, S., von Heijne, G. and Nielsen, H. (2011). SignalP 4.0: discriminating signal peptides from 
transmembrane regions. Nature methods, 8(10): 785-786.

Pradhan, A., and Olsson, P. E. (2015). Inhibition of retinoic acid synthesis disrupts spermatogenesis and fecundity in zebrafish. General and comparative endocrinology, 217: 81-91.

Rausell, A., Juan, D., Pazos, F. and Valencia, A. (2010). Protein interactions and ligand binding: from protein subfamilies to functional specificity. Proceedings of the National Academy of Sciences, 107(5): 1995-2000.

Ray, W. J., Bain, G., Yao, M., and Gottlieb, D. I. (1997). CYP26, a novel mammalian cytochrome P450, is induced by retinoic acid and defines a new family. Journal of Biological Chemistry, 272(30): 18702-18708.

Ray, W. J., Bain, G., Yao, M., and Gottlieb, D. I. (1997). CYP26, a novel mammalian cytochrome $\mathrm{P} 450$, is induced by retinoic acid and defines a new family. Journal of Biological Chemistry, 272(30): 18702-18708.

Rodríguez-Marí, A., Cañestro, C., BreMiller, R. A., Catchen, J. M., Yan, Y. L., and Postlethwait, J. H. (2013). Retinoic acid metabolic genes, meiosis, and gonadal sex differentiation in zebrafish. PloS one, 8(9): e73951.

Ross, S.A., McCaffery, P.J., Drager, U.C. and De Luca, L.M. (2000). Retinoids in embryonal development. Physiological reviews, 80(3), pp.1021-1054.

Roy, A., Kucukural, A. and Zhang, Y. (2010). I-TASSER: a unified platform for automated protein structure and function prediction. Nature protocols, 5(4): 725-738.

S.C. Lovell, I.W. Davis, W.B. Arendall III, P.I.W. de Bakker, J.M. Word, M.G. Prisant, J.S. Richardson and D.C. Richardson (2002). Structure validation by Calpha geometry: phi, psi and Cbeta deviation. Proteins: Structure, Function and Genetics. 50: 437-450.

Sharma, K., Yadava, N. K. and Jindal, M. (2010). Effect of different doses of ovatide on the breeding performance of Clarias batrachus (Linn.). Livestock research for rural development, 22(4): 2010.

Shimshoni, J. A., Roberts, A. G., Scian, M., Topletz, A. R., Blankert, S. A., Halpert, J. R., Nelson, W. L. and Isoherranen, N. (2012). Stereoselective formation and metabolism of 4-hydroxy-retinoic Acid enantiomers by cytochrome p450 enzymes. Journal of Biological Chemistry, 287(50): 42223-42232.

Szklarczyk, D., Franceschini, A., Wyder, S., Forslund, K., Heller, D., Huerta-Cepas, J., Simonovic, M., Roth, A., Santos, A., Tsafou, K.P. and Kuhn, M. (2014). STRING v10: protein-protein interaction networks, integrated over the tree of life. Nucleic acids research, 43(D1): D447-D452.

Topletz, A. R., Thatcher, J. E., Zelter, A., Lutz, J. D., Tay, S., Nelson, W. L., and Isoherranen, N. (2012). Comparison of the function and expression of CYP26A1 and CYP26B1, the two retinoic acid hydroxylases. Biochemical pharmacology, 83(1): 149-163.

White, J. A., Beckett-Jones, B., Guo, Y. D., Dilworth, F. J., Bonasoro, J., Jones, G., and Petkovich, M. (1997). cDNA cloning of human retinoic acidmetabolizing enzyme (hP450RAI) identifies a novel family of cytochromes P450 (CYP26). Journal of Biological Chemistry, 272(30): 18538-18541.

White, J.A., Guo, Y.D., Baetz, K., BeckettJones, B., Bonasoro, J., Hsu, K.E., Dilworth, F.J., Jones, G. and Petkovich, M. (1996). Identification of the retinoic acid-inducible all-trans-retinoic acid 4hydroxylase. Journal of Biological Chemistry, 271(47): 29922-29927. 
Xi, J., Yue, J., and Yang, Z. (2015). Expression profiles of retinoic acid synthetases ALDH1As and metabolic enzymes CYP26s in adult and embryonic zebrafish (Danio rerio). Genetics and Molecular Research, 14(2): 3948-3956.

Yashiro, K., Zhao, X., Uehara, M., Yamashita, K., Nishijima, M., Nishino, J., Saijoh, Y., Sakai, Y. and Hamada, H.

(2004). Regulation of retinoic acid distribution is required for proximodistal patterning and outgrowth of the developing mouse limb. Developmental cell, 6(3): 411-422.

Zhao, Q., Dobbs-McAuliffe, B., and Linney, E. (2005). Expression of cyp26b1 during zebrafish early development. Gene expression patterns, 5(3): 363369.

\section{How to cite this article:}

Deepak Agarwal, P. Gireesh-Babu, Vandita Kohli, Om Pravesh K. Ravi, Srijit Chakravarty, Adnan Gora and Aparna Chaudhari. 2018. Molecular Cloning of Retinoic-Acid Metabolizing Cytochrome P450 26B1 (Cyp26B1) and Expression Analysis during Different Reproductive Phase in Clarias magur (Hamilton 1822). Int.J.Curr.Microbiol.App.Sci. 7(08): 452-471. doi: https://doi.org/10.20546/ijcmas.2018.708.051 